\title{
PENGARUH MODEL PEMBELAJARAN INKUIRI TERBIMBING TERHADAP KETERAMPILAN PROSES SAINS SISWA
}

\author{
Susilawati ${ }^{1}$, Susilawati ${ }^{2}$, dan Nyoman Sridana ${ }^{3}$ \\ ${ }^{1}$ Magister Pendidikan IPA Universitas Mataram \\ ${ }^{2 \& 3}$ Fakultas Keguruan dan Ilmu Pendidikan Universitas Mataram \\ susi.sila62@yahoo.com
}

\begin{abstract}
Abstrak
Penelitian ini bertujuan untuk mengetahui perbedaan keterampilan proses sains siswa yang mengikuti model pembelajaran inkuiri terbimbing dengan pembelajaran konvensional. Jenis penelitian yang digunakan adalah penelitian eksperimen semu (Quasi experimental research). Penelitian dilaksanakan di SMPN 10 mataram tahun pelajaran 2014/2015. Sampel penelitian ini diambil dengan teknik cluster random sampling sejumlah 62 siswa terdiri dari satu kelas eksperimen dan satu kelas kontrol dengan perlakuan yang berbeda. Instrumen penelitian berupa lembar observasi keterampilan proses sains. Data hasil penelitian dianalisis dengan teknik anakova untuk menguji pengaruh model pembelajaran terhadap keterampilan proses sains. Analisis dilakukan dengan menggunakan program SPSS versi 20 for Windows. Berdasarkan hasil analisis diperoleh kesimpulan ada perbedaan keterampilan proses sains siswa yang mengikuti model pembelajaran inkuiri terbimbing dengan pembelajaran konvensional.
\end{abstract}

Kata Kunci: Model Pembelajaran Inkuiri Terbimbing, Keterampilan Proses Sains 


\section{PENDAHULUAN}

Proses pembelajaran IPA menekankan pada pemberian pengalaman langsung untuk mengembangkan kompetensi agar menjelajahi dan memahami alam sekitar secara ilmiah. Proses pembelajaran seperti ini menuntut agar dalam kegiatan belajar mengajar siswa tidak lagi berperan pasif hanya mendengarkan penjelasan guru dan mencatat hal-hal yang dianggap penting.

Pendekatan pembelajaran IPA hendaknya tidak lagi terlalu berpusat pada pendidik (teacher centered) melainkan harus lebih berorientasi pada peserta didik (student centered). Peranan pendidik perlu bergeser dari menentukan apa yang harus dipelajari menjadi bagaimana menyediakan dan memperkaya pengalaman belajar peserta didik. Pengalaman belajar bagi peserta didik dapat diperoleh melalui serangkaian kegiatan mengeksplorasi lingkungan melalui interaksi aktif dengan teman sejawat dan seluruh lingkungan belajarnya. Dalam mewujudkan hal tersebut perlu adanya suatu model pembelajaran inovatif yang diterapkan dalam pembelajaran IPA (Jufri, 2010).

Model pembelajaran inkuiri merupakan salah satu model pembelajaran yang mengacu pada kurikulum 2013. Menurut Straits dan Wilke model pembelajaran inkuiri merupakan salah satu model pembelajaran yang berperan penting dalam membangun paradigma pembelajaran konstruktivistik yang menekankan pada keaktifan belajar peserta didik (Jufri, 2010). Dalam proses pembelajaran, seluruh aktivitas yang dilakukan siswa diarahkan untuk mencari dan menemukan jawaban sendiri dari suatu yang dipertanyakan, sehingga diharapkan dapat meningkatkan keterampilan proses sains (Sanjaya, 2012). Dalam kegiatan model pembelajaran inkuiri, siswa dilatih untuk melakukan suatu percobaan, antara lain merumuskan masalah, mengajukan dan menguji hipotesis, menentukan variabel, merancang dan merakit instrument, mengumpulkan, mengolah dan menafsirkan data, menarik kesimpulan serta mengkomunikasikan hasil percobaan secara lisan dan tertulis. Keterampilan-keterampilan tersebut dapat disebut juga keterampilan proses sains.

28 BIOTA: Jurnal Tadris IPA Biologi FITK IAIN Mataram 
Keterampilan proses sains merupakan seperangkat keterampilan yang digunakan para ilmuwan dalam melakukan penyelidikan ilmiah (Kemendikbud, 2013). Keterampilan proses perlu dikembangkan dalam pembelajaran IPA karena mampu menjembatani tercapainya tujuan pembelajaran IPA melalui pemberian pengalaman langsung melalui penyelidikan ilmiah.

Berdasarkan pengalaman dan pengamatan peneliti sebagai guru di SMPN 10 Mataram bahwa proses pembelajaran IPA umumnya masih menggunakan pola pembelajaran yang bersifat teacher centered, dimana peranan guru masih mendominasi proses kegiatan pembelajaran, guru masih menjadi pusat informasi dan masih kurang melibatkan siswa secara aktif mencari dan menemukan informasi sendiri sehingga siswa cenderung bosan dan mengantuk di kelas.

Berdasarkan uraian di atas, maka tujuan penelitian ini adalah untuk mengetahui perbedaan keterampilan proses sains siswa yang mengikuti model pembelajaran inkuiri terbimbing dengan model pembelajaran konvensional,

\section{METODE PENELITIAN}

Jenis penelitian yang digunakan pada penelitian ini adalah penelitian eksperimen semu (Quasi experimental research). Populasi dalam penelitian ini adalah siswa kelas VIII SMPN 10 Mataram yang berjumlah 380 siswa. Sampel yang diambil adalah 2 kelas yaitu kelas VIII-I sebagai kelas kontrol dan kelas VIII-H sebagai kelas eksperimen. Pada kelas eksperimen diberikan perlakuan menggunakan model pembelajaran inkuiri terbimbing sedangkan pada kelas kontrol diberikan perlakuan model pembelajaran konvensional. Teknik pengambilan sampel secara Cluster Random Sampling.

Instrumen yang digunakan dalam penelitian ini adalah lembar observasi keterampilan proses sains digunakan untuk mengukur keterampilan proses sains siswa pada materi indra penglihatan dan alat optik. Observasi dilakukan oleh observer pada masing-masing kelompok siswa pada saat proses kegiatan 
pembelajaran berlangsung. Adapun indikator yang digunakan adalah mengamati, mengajukan pertanyaan, merencanakan percobaan, menggunakan alat/bahan percobaan, dan mengkomunikasikan. Selanjutnya data hasil penelitian dianalisis menggunakan ANACOVA dengan bantuan SPSS versi 20 for windows pada taraf signifikansi $5 \%$.

\section{HASIL}

Deskripsi data keterampilan proses sains pada kelas eksperimen dan kelas kontrol disajikan dalam tabel 1.

Tabel 1

Deskripsi Data Keterampilan Proses Sains Siswa

\begin{tabular}{|l|c|c|c|c|}
\hline \multirow{2}{*}{\multicolumn{2}{|c|}{ Sumber Data }} & \multicolumn{2}{c|}{ Kelas Eksperimen } & \multicolumn{2}{c|}{ Kelas Kontrol } \\
\cline { 2 - 5 } & Mean & $\begin{array}{c}\text { Std. } \\
\text { deviasi }\end{array}$ & Mean & $\begin{array}{c}\text { Std. } \\
\text { deviasi }\end{array}$ \\
\hline Mengamati & 67,35 & 18,546 & 57,38 & 21,186 \\
\hline Mengajukan Pertanyaan & 59,31 & 18,745 & 48,33 & 20,417 \\
\hline Merencanakan Percobaan & 66,27 & 18,87 & 56,31 & 21,379 \\
\hline $\begin{array}{l}\text { Menggunakan alat/bahan } \\
\text { percobaan }\end{array}$ & 66,37 & 18,952 & 56,90 & 19,875 \\
\hline Mengkomunikasikan & 62,84 & 17,274 & 50,60 & 18,923 \\
\hline Total Aspek KPS & 64,43 & 18,247 & 53,90 & 20,002 \\
\hline
\end{tabular}

Tabel 1 menunjukkan bahwa nilai rata-rata aspek keterampilan proses sains dan total aspek keterampilan proses sains pada kelas eksperimen lebih tinggi daripada kelas kontrol baik dari aspek mengamati, menanya, merencanakan percobaan, menggunakan alat/bahan percobaan, maupun mengkomunikasikan. Artinya ada peningkatan keterampilan proses sains siswa yang mendapat perlakuan dengan model pembelajaran inkuiri terbimbing.

30 BIOTA: Jurnal Tadris IPA Biologi FITK IAIN Mataram 
Data rata-rata aspek keterampilan proses sains kelas eksperimen dan kelas kontrol dapat ditampilkan dalam bentuk gambar diagram 1 sebagai berikut.

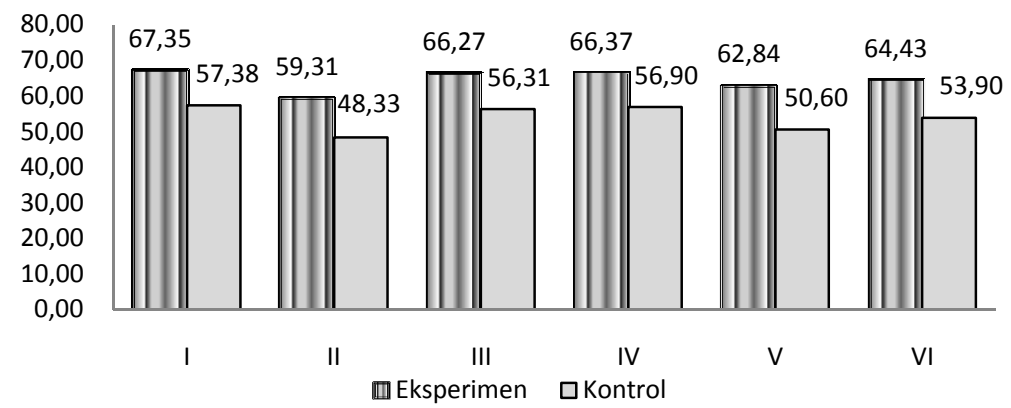

I : Mengamati, II : Menanya, III : Merencanakan Percobaan, IV : Menggunakan alat/bahan percobaan, V : Mengkomunikasikan, V : Total Aspek KPS

\section{Gambar 1}

Diagram Aspek Keterampilan Proses Sains

Berdasarkan Perlakuan Kelas

\section{Hasil Uji Prasyarat}

a. Uji Normalitas

Hasil uji normalitas data dilakukan dengan uji chi-square berbantuan program SPSS versi 20 for Windows. Keputusan uji dapat dinyatakan normal jika memenuhi syarat (Sig > 0.05) atau $\left(\mathrm{X}^{2}\right.$ hitung $<\mathrm{X}^{2}$ tabel $)$.

Tabel 2

Hasil Uji Normalitas Data Aspek Keterampilan Proses Sains

\begin{tabular}{|l|c|c|c|l|}
\hline \multicolumn{1}{|c|}{ Nama Data } & $\mathrm{X}^{2}$ hitung & $\begin{array}{c}\text { Asymp } \\
\text {.Sig }\end{array}$ & $\mathrm{X}^{2}$ tabel & \multicolumn{1}{|c|}{ Keputusan Uji } \\
\hline Mengamati & 24,065 & .344 & 33,924 & $\begin{array}{l}\mathrm{X}^{2} \text { hitung }<\mathrm{X}^{2} \text { tabel (data } \\
\text { Terdistribusi Normal) }\end{array}$ \\
\hline $\begin{array}{l}\text { Mengajukan } \\
\text { Pertanyaan }\end{array}$ & 33,097 & .045 & 32,671 & $\begin{array}{l}\mathrm{X}^{2} \text { hitung }>\mathrm{X}^{2} \text { tabel (data Tidak } \\
\text { Terdistribusi Normal) }\end{array}$ \\
\hline
\end{tabular}




\begin{tabular}{|l|l|c|c|l|}
\hline $\begin{array}{l}\text { Merancang } \\
\text { Percobaan }\end{array}$ & 20,355 & .561 & 33,924 & $\begin{array}{l}\mathrm{X}^{2} \text { hitung }<\mathrm{X}_{\text {tabel }} \text { (data } \\
\text { Terdistribusi Normal) }\end{array}$ \\
\hline $\begin{array}{l}\text { Menggunakan Alat } \\
\text { Percobaan }\end{array}$ & 28,097 & .107 & 31,410 & $\begin{array}{l}\mathrm{X}^{2} \text { hitung }<\mathrm{X}^{2} \text { tabel } \text { (data } \\
\text { Terdistribusi Normal) }\end{array}$ \\
\hline $\begin{array}{l}\text { Mengkomunikasika } \\
\mathrm{n}\end{array}$ & 34,452 & .044 & 33,924 & $\begin{array}{l}\mathrm{X}^{2} \text { hitung }>\mathrm{X}^{2} \text { tabel (data tidak } \\
\text { Terdistribusi Normal) }\end{array}$ \\
\hline Total Aspek KPS & 22,613 & .994 & 58,124 & $\begin{array}{l}\mathrm{X}^{2} \text { hitung }<\mathrm{X}_{\text {tabel }} \text { (data } \\
\text { Terdistribusi Normal) }\end{array}$ \\
\hline
\end{tabular}

b. Uji Homogenitas

Hasil uji homogenitas data dilakukan dengan uji $F$ berbantuan program SPSS versi 20 for Windows. Keputusan uji dapat dinyatakan homogen jika memenuhi syarat $(\mathrm{Sig}>0.05)$ atau $\left(\mathrm{F}_{\text {hitung }}<\mathrm{F}_{\text {tabel }}\right)$.

Tabel 3

Hasil Uji Homogenitas Data Keterampilan Proses Sains

\begin{tabular}{|c|c|c|c|c|c|}
\hline \multirow{2}{*}{ Nama Data } & \multirow{2}{*}{$F_{\text {hitung }}$} & \multicolumn{2}{|c|}{$\mathrm{df}=\mathrm{N}-1$} & \multirow{2}{*}{$\mathrm{F}_{\text {tabel }}$} & \multirow{2}{*}{ Keputusan Uji } \\
\hline & & $\mathrm{df}_{1}$ & $\mathrm{df}_{2}$ & & \\
\hline Aspek Mengamati & 1,305 & 27 & 33 & 1,827 & $\begin{array}{l}\mathrm{F}_{\text {hitung }}<\mathrm{F}_{\text {tabel, }} \\
\text { Homogen }\end{array}$ \\
\hline $\begin{array}{l}\text { Aspek Mengajukan } \\
\text { Pertanyaan }\end{array}$ & 1,186 & 27 & 33 & 1,827 & $\begin{array}{l}F_{\text {hitung }}<\mathrm{F}_{\text {tabel, }} \\
\text { Homogen }\end{array}$ \\
\hline $\begin{array}{l}\text { Aspek Merancang } \\
\text { Percobaan }\end{array}$ & 1,284 & 27 & 33 & 1,827 & $\begin{array}{l}F_{\text {hitung }}<\mathrm{F}_{\text {tabel, }} \\
\text { Homogen }\end{array}$ \\
\hline $\begin{array}{l}\text { Aspek Menggunakan Alat } \\
\text { Percobaan }\end{array}$ & 1,100 & 27 & 33 & 1,827 & $\begin{array}{l}\mathrm{F}_{\text {hitung }}<\mathrm{F}_{\text {tabel, }} \\
\text { Homogen }\end{array}$ \\
\hline Aspek Berkomunikasi & 1,200 & 27 & 33 & 1,827 & $\begin{array}{l}\mathrm{F}_{\text {hitung }}<\mathrm{F}_{\text {tabel, }} \\
\text { Homogen }\end{array}$ \\
\hline Total Aspek KPS & 1,202 & 27 & 33 & 1,827 & $\begin{array}{l}\mathrm{F}_{\text {hitung }}<\mathrm{F}_{\text {tabel, }} \\
\text { Homogen }\end{array}$ \\
\hline
\end{tabular}

\section{Hasil Uji Hipotesis}

Hasil uji hipotesis keterampilan proses sains pada taraf signifikan 5\% dapat ditampilkan pada tabel 4 .

32 BIOTA: Jurnal Tadris IPA Biologi FITK IAIN Mataram 
Tabel 4

Hasil Uji Hipotesis Keterampilan Proses Sains

\begin{tabular}{|c|c|c|c|c|l|}
\hline Sumber Data & F $_{\text {hitung }}$ & Sig. & df & $F_{\text {tabel }}$ & Keputusan \\
\hline Perlakuan Kelas & 4,815 & 0.032 & 1 & 3,998 & $\begin{array}{l}\mathrm{H}_{\mathrm{a}} \\
\text { diterima }\end{array}$ \\
\hline
\end{tabular}

Hasil uji hipotesis menunjukkan bahwa ada perbedaan keterampilan proses sains siswa yang mengikuti model pembelajaran inkuiri terbimbing (skor rata-rata 64,43) dengan pembelajaran konvensional (skor rata-rata 53,90). ( $\mathrm{F}_{\text {hitung }}$ $(4,815)>F_{\text {tabel }}(3,998)$ dan $\left.\operatorname{sig}(0.032)<0.05\right)$.

\section{PEMBAHASAN}

Hasil penelitian ini menunjukkan bahwa siswa yang mendapatkan pembelajaran dengan model pembelajaran inkuiri terbimbing secara keseluruhan memperoleh keterampilan proses sains lebih baik dibandingkan dengan siswa yang mendapatkan pembelajaran dengan model pembelajaran konvensional. Tingginya perolehan nilai rata-rata kelas eksperimen disebabkan karena model pembelajaran inkuiri terbimbing mengarahkan siswa pada berbagai aktifitas keterampilan proses seperti mengamati, merumuskan masalah dan hipotesis, mengajukan pertanyaan, merencanakan percobaan, menggunakan alat/bahan percobaan, dan mengkomunikasikan. Hal ini sejalan dengan Jufri \& Jekti (2010) yang menyatakan bahwa salah satu karakteristik khas dari kegiatan inkuiri dalam bidang sains adalah pemberian peluang bagi siswa untuk berlatih merumuskan masalah dan hipotesis, merancang eksperimen, menginterpretasi data dan berlatih mengkomunikasikan hasil kegiatan belajarnya. Hal senada juga dikemukakan Rustaman (2005) Proses inkuiri melibatkan seluruh aktivitas saintis untuk memperoleh informasi seperti berhipotesis, meramalkan, membaca, merencanakan dan melaksanakan eksperimen serta bekerjasama dengan saintis 
lainnya. Dalam melakukan aktivitas-aktivitas yang terkait dengan sains tersebut biasa disebut dengan keterampilan proses sains. Penelitian yang dilakukan Tangkas (2012) menyatakan bahwa pencapaian keterampilan proses sains siswa yang belajar dengan menggunakan model pembelajaran inquiri terbimbing memberikan hasil yang lebih optimal dibandingkan siswa yang belajar dengan menggunakan model pembelajaran langsung. Selanjutnya Ambarsari (2012) menyatakan pendekatan inkuiri merupakan pendekatan yang mampu menciptakan pembelajaran yang lebih efektif dibandingkan pendekatan konvensional. Pada pendekatan inkuiri siswa lebih banyak melakukan aktivitas dalam belajar dibandingkan pada pendekatan konvensional dan mampu meningkatkan keterampilan proses sains dasar aktivitas inkuiri memberikan peluang yang cemerlang untuk membangun pengetahuan melalui diskoveri.

Untuk memperkuat hasil penelitian ini, maka dilakukan uji pengaruh model pembelajaran (Inkuiri terbimbing dan konvensional) terhadap 5 aspek keterampilan proses sains. Pengujian hipotesis terhadap 5 aspek keterampilan proses sains menggunakan anakova dan Mann-Whitney karena ada 2 aspek yang tidak memenuhi uji prasyarat sehingga dilakukan dengan pengujian Mann-Whitney. Hasil pengujian hipotesis terhadap aspek mengamati, merencanakan percobaan dan mengkomunikasikan menyatakan bahwa ada perbedaan aspek keterampilan proses sains antara siswa yang mengikuti model pembelajaran inkuiri terbimbing dengan model pembelajaran konvensional. Hal ini terlihat juga pada nilai rata-rata aspek keterampilan proses sains kelas eksperimen (mengamati $(67,35)$, merencanakan percobaan (66,27), dan mengkomunikasikan $(62,84))$ lebih tinggi daripada nilai rata-rata kelas kontrol (mengamati $(57,38)$, merencanakan percobaan $(56,31)$, dan mengkomunikasikan $(50,60))$. Sedangkan hasil pengujian hipotesis terhadap aspek mengajukan pertanyaan dan menggunakan alat/bahan percobaan menyatakan bahwa tidak ada perbedaan antara siswa yang mengikuti model pembelajaran inkuiri terbimbing dengan model pembelajaran konvensional terhadap aspek keterampilan proses sains. Akan tetapi pada nilai

34 BIOTA: Jurnal Tadris IPA Biologi FITK IAIN Mataram 
rata-rata aspek keterampilan proses sains kelas eksperimen (mengajukan pertanyaan $(59,31)$ dan menggunakan alat/bahan percobaan $(66,37)$ ) lebih tinggi daripada nilai rata-rata kelas kontrol (mengajukan pertanyaan $(48,33)$ dan menggunakan alat/bahan percobaan $(56,90)$ ), sehingga dapat dikatakan bahwa dalam penelitian ini siswa masih belum mampu menguasai seluruh aspek keterampilan proses sains. Hal ini senada dengan penelitian yang dilakukan Maknun, dkk (2012) yang menyatakan bahwa sebagian besar mahasiswa calon guru biologi di jurusan Tadris IPA Biologi Fakultas Tarbiyah IAIN Syekh Nurjati Cirebon belum menguasai keterampilan esensial laboratorium (keterampilan proses sains) dengan baik.

\section{KESIMPULAN}

Berdasarkan hasil penelitian dan pembahasan, maka hasil penelitian ini dapat disimpulkan bahwa ada perbedaan keterampilan proses sains siswa yang mengikuti model pembelajaran inkuiri terbimbing dengan pembelajaran konvensional.

\section{DAFTAR PUSTAKA}

Ambarsari, W dkk. 2012. Penerapan Pembelajaran Inkuiri Terbimbing Terhadap Keterampilan Proses Sains Dasar pada Pelajaran Biologi Siswa Kelas VIII SMP Negeri 7 Surakarta. Jurnal Pendidikan Biologi Universitas Sebelas Maret Surakarta.

Jufri, W \& Jekti, DSD. 2010. Efektivitas Pembelajaran Sains Berbasis Inkuiri dengan Strategi Kooperatif dalam meningkatkan keterampilan Berfikir Siswa SMP. Jurnal Pendidikan dan Pembelajaran volume 17 Nomor 2. Universitas Mataram.

Jufri, W. 2010. Belajar dan Pembelajaran Sains. Mataram: Arga Puji Press. 
Maknun, D dkk. 2012. Pemetaan Keterampilan Esensial Laboratorium dalam Kegiatan Praktikum Ekologi. Jurnal Pendidikan IPA Indonesia. JPII 1 (1).

Rustaman. 2005. Pembelajaran Berbasis Inkuiri Dalam Pendidikan Sain. Makalah dalam seminar Nasional II. UPI

Sanjaya, W. 2012. Strategi Pembelajaran Berorientasi Standar Proses Pendidikan. Jakarta :Kencana Prenada Media Group.

Tangkas. 2012. Pengaruh Implementasi Model Pembelajaran Inkuiri Terbimbing Terhadap Kemampuan Pemahaman Konsep dan Keterampilan Proses Sains Siswa Kelas X SMAN 3 Amlapura. Jurnal Tesis. Program Studi Pendidikan Sains, Program Pascasarjana Universitas Pendidikan Ganesha. 